EGU2020-11931, updated on 21 Apr 2020

https://doi.org/10.5194/egusphere-egu2020-11931

EGU General Assembly 2020

(c) Author(s) 2020. This work is distributed under

the Creative Commons Attribution 4.0 License.

\title{
ENSO sensitivity to radiative forcing
}

\author{
Evgeniya Predybaylo ${ }^{1}$, Georgiy Stenchikov ${ }^{2}$, Andrew Wittenberg ${ }^{3}$, and Sergey Osipov ${ }^{1}$ \\ ${ }^{1}$ Max Planck Institute for Chemistry, Mainz, 55128, Germany \\ ${ }^{2}$ King Abdullah University of Science and Technology, Earth Science and Engineering, Thuwal Jeddah, Saudi Arabia \\ (evgeniya.predybaylo@kaust.edu.sa) \\ ${ }^{3}$ NOAA Geophysical Fluid Dynamics Laboratory, Princeton, NJ 08540, USA
}

To improve El Niño / Southern Oscillation (ENSO) predictions and projections in a changing climate, it is essential to better understand ENSO's sensitivities to external radiative forcings. Strong volcanic eruptions can help to clarify ENSO's sensitivities, mechanisms, and feedbacks. Strong explosive volcanic eruptions inject millions of tons of sulfur dioxide into the stratosphere, where they are converted into sulfate aerosols. For equatorial volcanoes, these aerosols can spread globally, scattering and absorbing incoming sunlight, and inducing a global-mean surface cooling. Despite this global-mean cooling effect, paleo data confirm remarkable warming of the eastern equatorial Pacific in the two years after a tropical eruption, with a shift towards an El Niñolike state. To illuminate this response and explain why it tends to occur during particular seasons and ENSO phases, we present a unified framework that includes the roles of the seasonal cycle, stochastic wind forcing, eruption magnitude, and various tropical Pacific climate feedbacks. Analyzing over 20,000 years of large-ensemble simulations from the GFDL-CM2.1 climate model forced by volcanic eruptions, we find that the ENSO response comprises both stochastic and deterministic components, which vary depending on the perturbation season and the ocean preconditioning. For boreal winter eruptions, stochastic dispersion largely obscures the deterministic response, being the largest for the strong El Niño preconditioning. Deterministic El Niño-like responses to summer eruptions are well seen on neutral ENSO and weak to moderate El Niño preconditioning and grow with the eruption magnitude. The relative balance of these components determines the predictability and strength of the ENSO response. The results clarify why previous studies obtained seemingly conflicting results. 